\title{
A systematic PRISMA review of individuals with autism spectrum disorder in secure psychiatric care: prevalence, treatment, risk assessment and other clinical considerations
}

\author{
Clare S. Allely
}

Clare S. Allely is a Reader in Forensic Psychology at the School of Health Sciences, University of Salford, Manchester, UK; and an Affiliate Member of the Gillberg Neuropsychiatry Centre, Sahlgrenska Academy, University of Gothenburg, Gothenburg, Sweden.
Received 23 June 2017 Revised 7 September 2017 Accepted 20 September 2017

(C) Clare S. Allely, 2017. Published by Emerald Publishing Limited. This article is published under the Creative Commons Attribution (CC BY 4.0) licence. Anyone may reproduce, distribute, translate and create derivative works of this article (for both commercial \& non-commercial purposes), subject to full attribution to the original publication and authors. The full terms of this licence may be seen at http://creativecommons.org/ licences/by/4.0/legalcode

Compliance with ethical standards: there are no conflicts of interest to declare. The paper did not received any funding.

\begin{abstract}
Purpose - Patients with autism spectrum disorder (ASD) present with specific assessment, specific difficulties, needs and therapeutic issues and therefore are a challenging group for forensic services. Given the challenge that individuals with ASD present to forensic services, the suggested increase in the number of this group within this setting and the relatively little amount of research which suggests they face a number of difficulties within the prison environment, the purpose of this paper is to identify and review all the studies which have been carried out investigating any aspect of ASD in relation to secure hospital settings. Design/methodology/approach - Seven internet-based bibliographic databases were used for the present review. The review followed the Preferred Reporting Items for Systematic reviews and Meta-Analyses guidelines. Findings - A total of 12 studies were included in this review; 3 looked at the prevalence of ASD in secure psychiatric hospitals. One study evaluated the clinical utility of the AQ screening tool to assess self-reported autistic traits in secure psychiatric settings. Three explored any type of characteristics of patients with ASD detained in secure psychiatric hospitals. One study investigated the experiences or quality of life of patients with an ASD detained in secure psychiatric care. Two studies investigated awareness, knowledge and/or views regarding patients with ASD held by staff working within secure psychiatric hospitals. Lastly, three studies (one of which was also included in the prevalence category above) looked at the effectiveness of interventions or treatment of patients with ASD in secure psychiatric hospitals. Clinical recommendations and future research directions are discussed.

Originality/value - To the author's knowledge, this is the first review to explore what research has been carried out looking specifically at patients with ASD in relation to secure forensic settings.
\end{abstract}

Keywords Autism spectrum disorder, Secure hospital, Asperger's syndrome, High secure psychiatric hospital, HSPC, Secure forensic settings

Paper type Literature review

Autism spectrum disorders (ASDs) are neurodevelopmental disorders characterised by impairments in social reciprocal interactions and communication and restricted, repetitive pattern of interests and behaviour (American Psychiatric Association, 2000, 2013). The "true" prevalence of ASD is not known (Fernell et al., 2012). As highlighted by Lyall et al. (2017) in a recent paper, only one rigorous study of ASD prevalence in adults has been conducted to date (Brugha et al., 2011). This investigation, conducted in England in 2007, actively sampled adults from the community and it employed an active two-stage screening-confirmation approach which produced an estimate of ASD in 1 per cent in the general population. This prevalence is consistent with the findings from some other studies (e.g. Simonoff, 2012). The male-female ratio for ASD prevalence is between 4 and 5:1 in the general population (Fombonne, 2009). The Diagnostic Statistical Manual fifth edition's (DSM-V) (American Psychiatric Association, 2013) now defines two 
core areas of impairment in ASD (previously three core areas): "persistent deficits in social communication and social interaction" and "restricted, repetitive patterns of behavior, interests, or activities". Impairment to these two core areas varies across individuals in terms of symptoms and levels of severity. There has been much criticism over the proposed changes and final changes made in the DSM-V's new criteria for ASD (see Waterhouse, 2013; Wing et al., 2011; McPartland et al., 2012; Ritvo, 2012; Fernell et al., 2012). However, a thorough discussion of this is outside the scope of this review.

\section{Rates of overlap between intellectual disability (ID) and ASD}

ID and ASD are the most common developmental disorders and "combined, they affect between 3 and 5 per cent of the population" (Srivastava and Schwartz, 2014, p. 161). Postorino et al. (2016), in a recent paper investigating the prevalence of ID and ASD in an Italian sample of children and adolescents, cited a number of studies which have found that there is a frequent co-occurrence between ID and ASD, and that both these disorders have been argued to share genetic substrates (e.g. Bölte and Poustka, 2002; Bonora et al., 2014; Charman et al., 2011; Deth, 2012; Fombonne, 2003, 2009; Mefford et al., 2012; Nicholl et al., 2014; Srivastava and Schwartz, 2014). Srivastava and Schwartz (2014) also suggest that these two disorders are significantly likely to be associated, both biochemically and molecularly. Studies have found that as many as 70 per cent of individuals with ASDs have some level of ID while the other 30 per cent have some form of disability (e.g. speech, behaviour) which is not cognitive dysfunction (Mefford et al., 2012; Newschaffer et al., 2007; Wilkins and Matson, 2009). However, it is interesting to note studies which have looked at this from the other perspective - the prevalence of ASD in individuals with ID. About 10 per cent of individuals with ID have ASDs. Additionally, some ID conditions have been found to have a greater prevalence of co-occurrence with ASD than others (Srivastava and Schwartz, 2014).

However, Postorino et al. (2016) have argued that the studies published to date have reported a wide range of rates of ID prevalence in ASD - with reported prevalence ranging from 16.7 to 84 per cent (Baird et al., 2000, 2006; Bertrand et al., 2001; Bölte and Poustka, 2002; Bölte et al., 2009; Carlsson et al., 2013; Centers for Disease Control and Prevention, 2014; Chakrabarti and Fombonne, 2005; Charman et al., 2011; De Bildt et al., 2004; Fombonne, 2003; Gillberg et al., 1991; Keen and Ward, 2004; La Malfa et al., 2004; Magnússon and Saemundsen, 2001; Matson and Shoemaker, 2009; Miller et al., 2012; Oliveira et al., 2007). The majority of these studies main research focus, however, was examining the epidemiology of ASD rather than specifically investigating the rate of comorbidity of ID in individuals with ASD (Postorino et al., 2016). Despite the well-established high co-morbidity between ID and ASD, the present paper focuses on studies which specifically look at individuals with ASD because there has been relatively little research investigating ASD in the criminal justice system. However, there is a significant amount of research which has looked at ID in the criminal justice system (e.g. Ali et al., 2016; Boer et al., 2016; Cootes, 2016; Eadens et al., 2016; Murphy, Gardner, and Freeman, 2017; Murphy, Chiu, Triantafyllopoulou, Barnoux, Blake, Cooke, Forrester-Jones, Gore and Beecham, 2017). This study is interested in the particular experiences of individuals with ASD given their unique features, challenges and needs.

\section{ASD and offending behaviour}

The types of offending behaviours which have been found to be associated with offenders with ASD include: violent behaviour, sexual offending, fire setting, obsessive harassment (stalking) and computer/cyber-crimes (Ledingham and Mills, 2015; Sabet et al., 2015; Allely and Creaby-Attwood, 2016). It is important to highlight that most individuals with ASD are law-abiding (Murphy, 2017). There is no evidence to suggest that individuals with ASD have higher rates of offending behaviour (King and Murphy, 2014). However, it is important to draw attention to the increasing body of research which indicates that it is those individuals with ASD who also have psychiatric co-morbidities who are more at risk of engaging in offending behaviour (e.g. Chaplin et al., 2013). Some of the most common co-morbidities in individuals with ASD include: mood disorders such as depression and anxiety (e.g. Ghaziuddin et al., 2002; Hammond and Hoffman, 2014; Matson and Williams, 2014; Moss et al., 2015; Bruggink et al., 2016), and behavioural disorders including 
attention-deficit/hyperactivity disorder (ADHD) (e.g. Chen et al., 2015; Taylor et al., 2015; Antshel et al., 2016). One recent longitudinal study comprising of 124 youths with a clinical diagnosis of ASD (mean age, $10.6 \pm 3.3$ years - at the start of the study) found that early comorbid psychiatric conditions such as: anxiety/depression, inattention, hyperactivity/impulsivity and oppositional behaviours may also impair later social adjustment (adaptive functioning) in youths with ASD as found at follow up interviews which took place about three years later (37.59 \pm 15 months) (Chiang and Gau, 2016).

\section{$A S D$ in the prison environment}

While there have been numerous studies investigating the offending behaviour of individuals with ASDs, there has been very little research investigating the experience and difficulties faced by such individuals in the prison environment (Haskins and Silva, 2006; Lewis et al., 2015). Two recent reviews highlight the lack of research which has explored the experiences of individuals with ASD in the prison environment (Robertson and McGillivray, 2015; Allely, 2015). For inmates with ASD, numerous issues can result from the social and physical constraints of the prison environment. For individuals with ASD, the prison environment can be more challenging and distressing due to the ASD traits that can cause problems in everyday life (e.g. obsessions, compulsions, difficulties in communicating with others) (e.g. Love and Morrison, 2002; Martin, 2001; Newman et al., 2015). They may also be more vulnerable to bullying, exploitation, sexual and physical victimisation, social isolation and confrontations with other inmates (The National Autistic Society, 2005; English and Heil, 2005). Some studies have also found that having a development disability is a risk factor for encountering less empathy from correctional staff (Glaser and Deane, 1999; Shively, 2004) and for having relational difficulties with other inmates (Attwood, 1998; Gordon, 2002).

Currently, the prevalence of ASDs in prisons is not known (Robinson et al., 2012). There are a number of reasons why this figure is difficult to ascertain. The main reason was highlighted by Chaplin and McCarthy (2014) in their paper. Currently in the UK, ASD is not part of the prison screening process (Myers, 2004; Chaplin and McCarthy, 2014). A lack of suitable, ASD sensitive, assessment tools has been put forward as one possible explanation for this and the lack of screening presents as a significant problem throughout all stages of the criminal justice system (Myers, 2004; Cooper and Allely, 2017). Using the Autism Quotient (AQ-20), Underwood et al. (2016) identified high levels of unrecognised ASD traits among a group of male prisoners in an adult male prison in London in the UK (UK). Of the 186 adult males approached on the prison wings, 10 per cent screened positive and 2 per cent fulfilled the diagnostic criteria for ASD. Such findings strongly highlight the need for specialist assessment within the criminal justice system for individuals with neurodevelopmental disorders such as ASD. Based on this rate of 2 per cent, the Ministry of Justice (2015) suggests that in prisons in the UK there are approximately 1,600 men and 120 women with ASD (Ministry of Justice, 2015). Importantly, rates of ASD in prison may vary depending on its type (e.g. remanded or sentenced, high-secure, mainstream prisons, etc.) (Underwood et al., 2013).

Given that many individuals with ASDs have difficulties in being able to communicate their needs and are at increased risk for experiencing victimisation in the prison, it is crucial that prison staff have at least an adequate understanding of ASD (Jordan, 1999). There has been very little research in this area. In Scotland, Myers (2004) touched on the issue surrounding the knowledge and understanding of ASDs in prison staff. A recent review identified only one study (McAdam, 2009) which explored the knowledge and understanding of the ASD amongst prison staff (Allely, 2015). McAdam identified, within a six-month period, five prisoners with a diagnosis of an ASD (four with a diagnosis of Asperger's syndrome (AS) and one with autism). Also, three of the five individuals with ASD appeared to be struggling significantly with the prison environment. Using a survey questionnaire, McAdam investigated the knowledge and understanding of ASDs in 53 prison staff. The crucial finding of this study was the possibility that individuals with ASDs may not be receiving the care that they need within the prison environment.

\section{Aims of the present review}

Another interesting finding based on clinical experience and available evidence is that most individuals with ASD requiring secure care are likely to be on the higher functioning end of the

PAGE $60 \mid$ JOURNAL OF CRIMINAL PSYCHOLOGY $\mid$ VOL. 8 NO. 12018 
autism spectrum (Barkham et al., 2013). Murphy et al. have emphasised that patients with ASD present with specific assessment, specific difficulties, needs and therapeutic issues and therefore are a challenging group for forensic services (Murphy, 2010a; Murphy, Murphy, Mullens, and Mullens, 2017). Lastly, within secure hospital settings, Gunasekaran (2012) argued that there appears to be an increasing number of individuals identified with ASD. Given the challenge that individuals with ASD present to forensic services, the suggested increase in the number of this group within this setting and the relatively little amount of research which suggests they face a number of difficulties within the prison environment, the present review will investigate what studies have been carried out investigating any aspect of ASD in relation to secure hospital settings. For instance, studies investigating the prevalence, experiences, treatment outcomes, etc., in patients with ASD in secure forensic settings.

\section{Method}

Seven internet-based bibliographic databases were used for the present review including: Journals@Ovid Full Text 26 May 2017; PsycARTICLES Full Text; AMED (Allied and Complementary Medicine) 1985 to May 2017; HMIC Health Management Information Consortium 1979 to January 2017; PsycEXTRA 1908 to 15 May 2017; PsycINFO 2002 to May Week 4, 2017 and Ovid MEDLINE(R) Epub Ahead of Print, In-Process \& Other Non-Indexed Citations, Ovid MEDLINE(R) Daily, Ovid MEDLINE and Versions(R). No date limitations were placed on the search conducted on these databases above. These seven databases were searched in order to identify studies which investigated ASD within a secure psychiatric hospital/facility: for instance, studies which looked at the cognitive profile of individuals with ASD in secure settings, prevalence of ASD in secure settings, experiences of individuals with ASD in secure settings, views or knowledge of ASD in secure hospital staff, etc. Following a scoping search of the field, there were relatively few studies found across these areas. Given this, it was decided that this review would take a more inclusive approach to the literature. The flowchart in Figure 1 describes the process of eliminating non-relevant papers in the present review following Preferred Reporting Items for Systematic reviews and Meta-Analyses (PRISMA) guidelines (Liberati et al., 2009). The PRISMA guidelines were developed by an international group which consisted of experienced authors and methodologists. The PRISMA statement contains a 27-item checklist and a four-phase flow diagram. The checklist consists of items which are considered key to ensuring transparent reporting in a systematic review (Moher et al., 2009; Liberati et al., 2009).

Duplicates were excluded prior to the retrieval of references. Searches on all seven databases were conducted on the 26 May 2017. The following search criteria (using keywords) were entered into the seven databases using no date limits: (neurodevelopmental or ASD or autism or autistic or "autism spectrum*" or "asperger's syndrome" or asperger's or aspergers or "autistic spectrum condition" or "autism spectrum disorder*"mp. [mp =ti, ab, tx, ct, sh, hw, ot, id, tc, tm, nm, kf, px, rx, an, ui, sy] AND ("high secure psychiatric hospital*" or "high security psychiatric hospital*" or "high security hospital*" or "high secure hospital" or "secure hospital" or "high secure" or "secure care").mp. [mp =ti, ab, tx, ct, sh, hw, ot, id, tc, tm, nm, kf, px, rx, an, ui, sy].

The search returned 96 articles. There were five duplicates, and after these were removed, there were 91. Only, five articles found in the databases search meet the inclusion criteria of this review.

In addition to these database searches, numerous permutations of ASD and other search terms relating to the court process were entered into Google Scholar and thoroughly searched for articles which were not identified through the database searches, for instance, "high secure" AND autism; "high secure" AND Asperger's. The reference section was carefully examined for potential relevant studies in each systematic review, literature review or commentary paper. All references contained in the papers identified as relevant from the database searches were also examined for possible inclusion in this review. Searches on Google Scholar resulted in the identification of seven articles which met the inclusion criteria of this review. Given the relatively little research in this field, this review is more inclusion than exclusion.

In total, 12 articles meet the inclusion criteria and were included in this review.

\begin{tabular}{l|l|l} 
VOL. 8 NO. 12018 & JOURNAL OF CRIMINAL PSYCHOLOGY & PAGE 61
\end{tabular} 
Identification

Screening

Included

Eligibility
Number of additional references identified as relevant through other sources such as Google scholar searches - 7 (Additionally, all references contained in every relevant papereven review papers - identified in database search were examined for any relevant papers that meet the review inclusion criteria - not included in figure here) identified through
database search -96
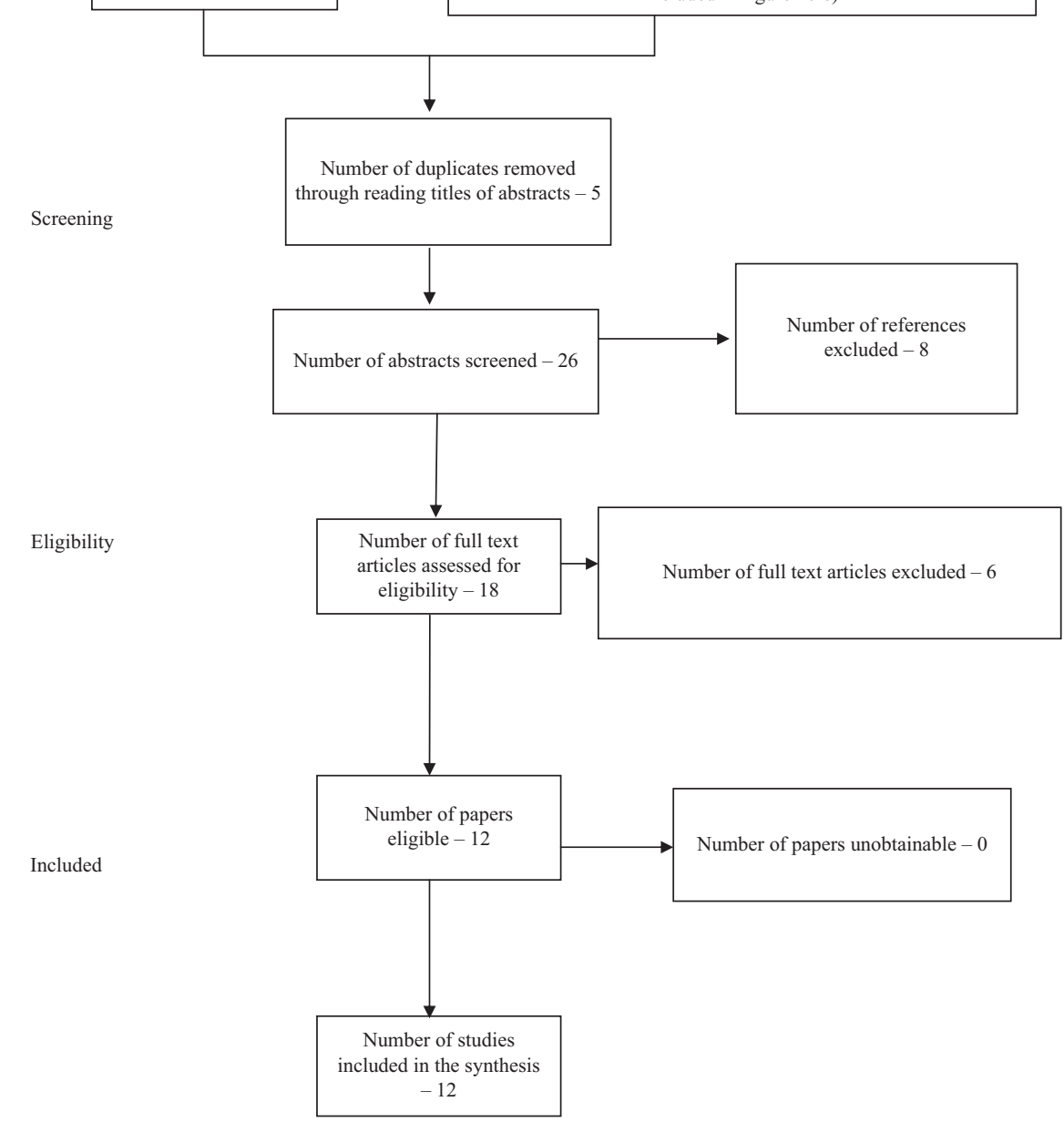

Abstracts for each reference were obtained and screened using the following criteria:

Inclusion criteria:

1. human study population; and

2. papers which investigated ASDs within a low, medium or high secure psychiatric hospital (or other terms to describe this such as high secure unit; high secure hospital, secure hospital, secure settings, etc.).

\section{Exclusion criteria:}

1. paper not published in English;

2. papers investigated did not focus on ASDs but intellectual disabilities or other disorders/ conditions such as personality disorders, etc.;

3. papers which report on cases of individuals with both intellectual disabilities and ASD;

4. papers which are not peer reviewed articles; and 
5. studies which do not investigate the cognitive profile of individuals with ASD in secure settings, prevalence of ASD in secure settings, experiences of individuals with ASD in secure settings, views or knowledge of ASD in secure hospital staff, etc.

\section{Results}

In total, 12 studies were identified which looked at some aspect of ASD within secure psychiatric hospitals. These studies were reviewed using the following six categories: prevalence of ASD in secure psychiatric hospitals; evaluating the clinical utility of the $A Q$ screening tool to assess self-reported autistic traits in secure psychiatric settings; characteristics of patients with ASD detained in secure psychiatric hospitals; experiences and quality of life (QoL) of patients with an ASD detained in secure psychiatric care; and awareness and views of ASD held by staff working within a secure psychiatric hospital and interventions/treatment outcomes with patients with ASD in secure psychiatric hospitals. It is interesting that the vast majority of studies identified and included in the review were conducted in the UK.

\section{Prevalence of ASD in secure psychiatric hospitals}

Only three peer reviewed articles were identified in the present review which explored the prevalence of ASD within secure environments. First, Scragg and Shah (1994) investigated the hypothesis that AS may go unrecognised in forensic settings. In their seminal study, they screened the entire male patient population $(n=392)$ in Broadmoor Special Hospital by examination of case notes in order to determine the prevalence of AS. Patients identified following the screening process were then observed and interviewed, and key staff members also took part in a semi-structured interview. The screening of the 392 patients (stage 1) produced 17 cases for stages 2 and 3 of the study. Six patients refused to meet the investigator. However, through interviews with members of staff and examination of these patients' medical files, detailed information was obtained on all 17 cases. Using all information collected through examination of case records and staff and patient interviews, a diagnosis was made. Of the 17 cases, six patients were found to fulfil the strict diagnostic criteria for AS (Gillberg and Gillberg, 1989). Three patients were equivocal, meaning that they met most but not all of the criteria, partly due to a lack of information. For two of the three equivocal patients, information was lacking on early childhood. The third equivocal patient refused to be interviewed. Characteristic features of ASD were exhibited in all three equivocal cases (Wing, 1991). The remaining eight cases were clearly not AS. The findings of six patients with a diagnosis of AS produces a prevalence rate of 1.5 per cent for this population. Interestingly, only two of these six patients had previously been diagnosed as having AS which indicates that AS is not always recognised (Scragg and Shah, 1994). The prevalence increases to 2.3 per cent if the three equivocal cases are included which is much greater compared to that found in males in the general population. The most conservative figure for the prevalence of AS in males in the general population was found by Ehlers and Gillberg (1993) to be 0.55 per cent. Given this, compared to the prevalence found in the general population, the prevalence of AS in Broadmoor Hospital is about three times greater. Examining the types of offences committed by the six men at Broadmoor diagnosed with AS, three had been physically violent, one had committed arson and two exhibited aggressive behaviour on the wards (e.g. feigning punches and threatening to cause injury to others).

In the second prevalence study, Hare et al. (1999) screened a total of 1,305 residents in the three special hospitals in the UK. Hare et al. screened 96 per cent of the special hospital population resident in the three hospitals. Using a score of five as the cut-off point for further investigation of a possible ASD resulting in a total of 240 patients across the three special hospitals (25 of the 240 patients could not be followed up in the second stage due to a variety of reasons such as patients being discharged). From the 215 cases of patients who scored over five on the screening questionnaire, 31 definite cases of autistic conditions were identified based on information in their hospital records (there were no significant differences across the three hospitals in the number of definite cases of ASD). A total of 31 cases equate to 2.4 per cent of the population screened. This is consistent with the higher estimate indicated by Scragg and Shah (1994) in the study they carried out in Broadmoor. There were also 31 equivocal cases. This "uncertain" group comprised 
of individuals where the diagnostic criteria was only partially met and/or where there was a lack of sufficient information to make a clear diagnosis of ASD. In the general population, the highest estimated rate for ASDs is 0.71 per cent for individuals with IQ greater than 70 (Wing, 1996). The lowest prevalence estimate for the special hospitals population (2.4 per cent) is more than three times the prevalence found in the general population. For all three groups, mean length of time in hospital was similar and as much as two to three years longer than the average of 8.5 years reported for patients detained in a special hospital (Taylor et al., 1998). Lastly, compared to the other groups, the group diagnosed as having ASDs had significantly more circumscribed interests and repetitive routines. Commonly reported circumscribed interests included violence, weapons and Nazism. The special interests were found in some of the cases to be directly related to the offence committed (Hare et al., 1999). Lastly, although this review is excluding studies which look at individuals with an ID as well as ASD, the following study was still included as it carried out a comparison between patients with ID with and without ASD. Esan et al. (2015) investigated the characteristics and prevalence of those with ASD treated within a 64-bed specialised forensic ID hospital in England compared to those without ASD. Of the 138 (cohort of patients treated over a six-year period), 42 (30 per cent) had an ASD (Esan et al., 2015). However, it is important to point out here that a number of studies and papers have highlighted the relatively high rate of intellectual disabilities in both children and adults with ASD in the general population/community samples (e.g. La Malfa et al., 2004; Matson and Shoemaker, 2009; Postorino et al., 2016; Tonnsen et al., 2016).

\section{Evaluating the clinical utility of the $A Q$ screening tool to assess self-reported autistic traits in secure psychiatric settings}

The autism spectrum quotient (AQ) (Baron-Cohen et al., 2001) is a self-report screening tool used to assess autistic traits. Murphy (2011) carried out a study which is the first examination of the $A Q$ among patients detained in high secure psychiatric care (HSPC). The researchers examined the profiles of 105 male patients detained within HSPC (about 47.7 per cent of the total patient population). The sample of patients comprised of three groups: mentally ill individuals with DSM-IV-defined psychotic disorders, such as paranoid schizophrenia, schizoaffective disorder (Ml group, $n=69$ ), a group with a range of different personality disorders including borderline and anti-social (PD group, $n=24$ ) and a group of patients with an ASD (ASD group, $n=12$ ). All patients in the study exhibited a Wechsler Adult Intelligence Scale III (WAIS III) (Wechsler, 1997) full scale IQ score above 70. Patients ranged in age from 19 to 66 years. Average age or performance on neuropsychology measures were not significantly different between the diagnostic groups. Findings revealed that the individuals with ASD exhibited significantly higher total AQ scores compared to those without a diagnosis of ASD. However, the social skill, communication and attention switching subscales of the AQ were found to be what significantly discriminated the patients with ASD from those with MI and PD. Interestingly, Murphy (2011) found that two of the AQ subscales, namely, attention to detail and imagination, seemed to have less discriminative validity in this population of patients. Murphy (2011) suggests that a possible explanation for this is that these subscales "reflect common features associated with institutionalised psychiatric patients, such as a need for routine, a sensitivity to change in their immediate environment, as well as perspective taking and empathy difficulties" (p. 529).

\section{Characteristics of patients with ASD detained in secure psychiatric hospitals}

Only three studies were identified which explored any type of characteristics of patients with ASD detained in secure psychiatric hospitals (Murphy, 2003, 2014; Haw et al. , 2013). Noting that there is a dearth of research and understanding of the characteristics of patients with ASD in secure care and how they compare to those from non-ASD populations, Haw et al. (2013) investigated the characteristics of male forensic patients with ASD in low-secure care and compared them to patients without ASD. Specifically, they used two ASD units (one in Northampton and the other in Birmingham) and one non-ASD unit at a tertiary referral centre. During the study period, there were 51 ASD patients admitted to the two ASD units. However, six sets of case notes could not be traced which resulted in a total of 45 ASD patients for inclusion in the study. The control group comprised all available 43 non-ASD low-secure admissions. Haw et al. found a number of 
significant differences between the groups. For instance, those with ASD were younger (median age of ASD patients was 27 vs 33 years for the controls). They were also younger at their first contact with psychiatric services. Interestingly, most patients with ASD were admitted from other hospitals. However, a substantial minority were admitted from prisons and courts. On the other hand, only two control group patients came from prison and the courts, with most of the other controls coming from other hospitals. Compared to the control group, a greater proportion of the ASD group were on Part III (forensic) sections of The Mental Health Act 2007 (MHA). In the group of ASD patients, 12 patients (26.7 per cent) only had a diagnosis of ASD, and 33 patients (73.3 per cent) had psychiatric co-morbidities. Specifically, schizophrenia and related psychotic disorders were the most common psychiatric comorbidities (a small number of patients also had learning disabilities and hyperkinetic disorder). In total, 17 (37.8 per cent) patients with ASD were subject to restriction orders. The ASD group were found to be less likely to have a diagnosis of alcohol or substance misuse or dependence and were also found to be less likely to have a personality disorder. A lifetime history of alcohol misuse was found in 37.8 per cent of patients with ASD and 55.8 per cent of controls (however, this was not found to be statistically significant). A lifetime history of drug misuse was less likely in the ASD group. A lifetime history of physical violence was found in 77.8 per cent of ASD patients but this was significantly lower compared to the control group (93.0 per cent). A lifetime history of self-harm was found in 37.8 per cent of the patients with ASD. This was lower than the control group (55.8 per cent) but not statistically significantly different. A history of repetitive self-injury was found in an additional five (11.1 per cent) patients with ASD. Compared to the controls, a lifetime history of sexually inappropriate behaviour was less common in the ASD group. In the cases involving sexually inappropriate behaviour, it was, sometimes, of an unusual nature. For instance, in the case involving voyeurism, the patient with ASD had repeatedly entered ladies' toilets to look into cubicles. Unusual index offences were found in some of the patients with ASD. For instance, stalking (one patient delivered razor blades in the post to an organisation which had not offered him a job), arson of an atypical nature (one patient set fire to a pile of his own clothes after being moved to a residential home he did not want to live in) or bizarre damage to property (one patient poured water into the computers at a job centre). Compared to the controls, in the ASD group, drug intoxication at the time of the index offence was less common. Findings revealed grievous bodily harm or homicide convictions in 33 per cent of the patients with ASD but only 16 per cent of the controls. Some studies have found that ASD offenders are less violent compared to other mentally disordered offenders. Murphy (2003) examined the violence ratings for offending behaviour of patients in an HSPC and found lower violence ratings for their index offence and offending history in the patients with ASD compared to those patients with mental illness or personality disorders. In Haw et al.'s study, there was no significant difference between the controls and the patients with ASD in terms of history of antisocial behaviour before the age of 18 years, age of first conviction and having served a custodial sentence. Patients with ASD did, however, have less prior convictions compared to the controls but this could be because of the age difference between the two groups (Haw et al., 2013).

Based on selected admission and neuropsychological details, Murphy (2003) investigated (using patient case notes) whether male patients with AS detained in an HSPC could be distinguished from patients with schizophrenia or with a personality disorder. The sample population comprised of 39 male patients detained in Broadmoor High-Security Hospital: 13 patients with either a clear or an equivocal diagnosis of AS, 13 patients with a diagnosis of schizophrenia (MI) and 13 patients with a personality disorder (PD) without any history of a psychotic illness. All Ml and PD patients were male and aged between 20 and 40 years, and they were selected at random from the same wards as those patients with AS in order to match the AS group. At the time of the study, the AS sample comprised of all male patients with a formal ASD diagnosis in the hospital. The greatest range of admission sections (five in total) was found in the Ml group. However, in the AS group, there were two s.3 (admission for treatment), one s.38 (interim hospital order) and ten s.37/49. In the AS group, the distribution of MHA 1983 classifications included: five with a PD classification and eight with an Ml classification. A history of alcohol and illicit substance abuse was found in most patients in the Ml and PD groups. In the AS group, only one patient had a history of illicit substance abuse - in this case, the drug was amphetamines. Compared to the PD group and the Ml group, the AS group had lower index offence (i.e. the offence which resulted in their admission 
to the hospital) and "total violence ratings" (i.e. the sum of violence ratings for an individual's index offence and offending history). Compared to those in the PD and Ml groups, the offences committed by individuals in the AS group tended to be less severe (i.e. less likely to involve offences where victims died or where victims' lives were seriously endangered, or which did not result in serious injury). These findings indicate that there are similarities and differences in specific admission and neuropsychological details between the patient groups. However, the key finding was the variation among individual profiles. Specifically, the patients with AS admitted to HSPC were found to be a complex group who were not able to be reliably distinguished from both the Ml and PD patients on the basis of their admission and neuropsychological details investigated in the present study. For instance, the AS and PD groups displayed similar neuropsychological profiles in some areas such as on the WAIS-R sub-test Digit Symbol which examines visual orientation and attention, concentration and visual shifting abilities (Murphy, 2003).

In a more recent study, Murphy (2014) investigated self-reported anger among individuals with an ASD detained in HSPC and whether preoccupations (POs) had an influence. The population sample consisted of 20 males with an ASD admitted to HSPC for assessment from January 2002 to December 2011. The PO group were individuals with offending (index offending) directly linked to pursuing an intense $\mathrm{PO}(n=10)$. The non-preoccupied offending group (NPO) were comprised of individuals whose offending appeared to be unrelated to a PO $(n=10)$ (Murphy, 2014). Findings revealed no significant differences in basic demographic and cognitive functioning details between the PO and NPO group. Based on the findings from the AQ and the experience and expression of anger based on the State trait expression of anger inventory (STAXI 2) (Spielberger, 1999), findings indicated that individuals with ASD whose index offending is associated with their PO may have a particular sensitivity towards attending to details in their immediate environment and may even exhibit more difficulties with expressing anger outwardly. Another interesting finding in this study was that the NPO group appeared to have more complex co-morbid psychiatric presentations (e.g. psychosis or a personality disorder) when compared to those whose offending behaviour was associated with pursuing a PO (80 vs 50 per cent) (Murphy, 2014).

\section{Experiences and QoL of patients with an ASD detained in secure psychiatric care}

In the first study of its kind, Murphy, Murphy, Mullens and Mullens (2017) investigated the experience of individuals with an ASD admitted to an HSPC hospital. This is the first study to investigate the experiences of patients with ASD in HSPC. Murphy et al. used both a semi-structured interview and a QoL self-report measure, the Lancashire Quality of Life Profile (Oliver et al., 1996) in order to examine the experiences and views of seven patients with an ASD detained in one HSPC hospital. The study identified a wide variety of both negative and positive aspects of being detained in HSPC from the patients interviewed. Patients with experience of prison thought HSPC was a less stressful environment with more "therapeutic opportunities". When compared to other detained forensic patient groups, patients with an ASD (as a group) reported a similar or significantly better QoL in a number of areas (including global, leisure, financial and living situation).

However, there are numerous practical improvements which could be implemented/integrated into secure hospitals in order to try and minimise the stress levels in patients with ASD and hopefully impact positively on therapeutic outcomes (Murphy, Chiu, Triantafyllopoulou, Barnoux, Blake, Cooke, Forrester-Jones, Gore and Beecham, 2017; Murphy, Gardner and Freeman, 2017; Murphy, Murphy, Mullens and Mullens, 2017). For instance, one of the hospital procedures described by some patients as difficult was having a limited time to eat meals. Loss of freedom and restrictions in what they are allowed in terms of personal possessions was reported as being extremely difficult for most patients with ASD admitted to HSPC. Restrictions in what they are allowed will be particularly challenging for patients with ASD whose items that are restricted are part of their specific interests. For instance, one patient in the study was not allowed a pair of binoculars to watch aircraft, which was a problem. About half of those interviewed reported significant stress due to the level of noise produced by other patients. Trying to get on with those viewed as being bullies or who had unpredictable mental states linked to their illness were also reported difficulties. Despite the majority of patients having lived on or being currently on wards

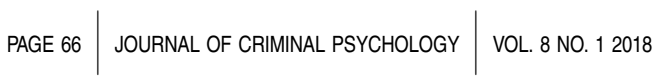


with between 12 and 20 other patients, all felt isolated and without friends. Some individuals were happy with this isolation while others reported wanting increased contact with others they could relate to. All patients reported wanting greater consistency with timetabled programmes and to avoid having activities cancelled. All patients interviewed reported being satisfied with the medical and psychological help they received in the hospital with the exception of just one patient. Additionally, nearly all those interviewed held the view that none of the staff or professionals they came into contact with before coming to HSPC had developed a good understanding of the personal difficulties that they faced (an experience particularly common in those from mainstream prisons, notably those admitted from a category A prison). The only exception to this view was those patients who had been re-admitted from a specialist medium secure ASD unit. All patients who have previous experience of being in a prison described them as being very noisy environments with little privacy. All individuals with ASD in the sample population reported that they felt unsafe from other prisoners in prisons. Consistent with the findings of an HSPC staff survey (Murphy and McMorrow, 2015, described below) are the comments by all patients regarding the importance of staff awareness of ASD and that it would be useful to have a specialist ASD ward in the hospital (Murphy, Murphy, Mullens, and Mullens, 2017).

\section{Awareness and views of ASD held by staff working within a secure psychiatric hospital}

Only two studies were identified which investigated awareness, knowledge and/or views regarding patients with ASD held by staff working within secure psychiatric hospitals (Misra et al., 2013; Murphy and McMorrow, 2015). In the first study, Murphy and McMorrow (2015) carried out a study to explore the views of ASD held by staff working within an HSPC hospital. The authors devised a 15-item questionnaire to explore views (on vulnerability, benefits from therapy and any adjustments they made to their practice), knowledge and training needs of staff in relation to ASD. A total of 206 questionnaires were returned (approximately 60 per cent of those distributed). Findings indicated that the majority of staff reported making adjustments in their practice and held the view that patients with ASD were more vulnerable compared to other patient groups. An important finding was that half of staff reported the view that even though patients with ASD received some degree of benefit from the therapies they engaged in, the staff felt that they were not aware if an individual's personal difficulties were taken into consideration in their care. Half of staff reported that patients with ASD should be managed differently. The majority of staff reported not having the necessary skills to work with ASD, expressed the wish for more training and argued that such training should be mandatory. With the exception of psychiatrists, the majority of the staff were not aware of the Autism Act (2009). Several staff reported the need for a specialist ASD ward within HSPC (Murphy and McMorrow, 2015). In the second study, Misra et al. (2013) carried out an audit in order to evaluate the need for specialist service for individuals with ASD within HSPC. The authors developed a questionnaire to investigate the clinical practice, willingness and knowledge of the Gold standards of care. The questionnaire was administered on nine wards to the staff on three different shifts. Based on the 100 completed forms returned, findings indicated that the majority of the staff were aware of ASD. However, most of the staff had not heard about "standard approach of care". The study also found that most staff were willing to train and work within a specialist ASD team (Misra et al., 2013). It must be pointed out here that there was only an abstract available for this study.

\section{Interventions/treatment outcomes with patients with ASD in secure psychiatric hospitals}

Only three studies were identified which investigated the effectiveness of interventions or treatment of patients with ASD in secure psychiatric hospitals (Murphy, 2010a; Esan et al., 2015; MacDonald et al., 2017). One of these studies (Esan et al., 2015) was included in the section above on prevalence of ASD in secure hospital settings. In the first study, Murphy (2010a) described the case study of a young man (AB) diagnosed with ASD who was convicted of manslaughter and admitted to HSPC. Several issues identified in the offence formulation were targeted through individual work with $\mathrm{AB}$. The individual work with $\mathrm{AB}$ involved education about $A S D$, the use of an adapted cognitive behaviour therapy and skill development in areas such as emotion recognition and general problem solving. Individual work with $A B$ also focussed on attempting to improve his difficulties with recognising and appreciating the consequences of his 
actions on others, victim empathy, dealing appropriately with interpersonal conflict and anger expression. This individual work was informed by evidence of best practice (e.g. Attwood, 2006; Gaus, 2007; Hare and Paine, 1997). AB was offered group work due to his marked impaired perspective-taking abilities and interpersonal anxieties. AB received over 70 hours of individual contact. However, the authors point out that the outcome of this individual work was "difficult to quantify". AB continued to hold an egocentric perspective. Specifically, he exhibited no victim empathy and maintained the view that his actions were justified. AB holds the view that there is a low chance of him re-offending. Despite this, $A B$ was found to have "significant difficulty with being able to generalise risks to other situations, recognise the association with violence and feeling stressed, as well as the importance of dealing with interpersonal conflict in an appropriate way" (p. 472). The case of AB (although significantly idiosyncratic) highlights just some of the issues surrounding clinical and risk management which are relevant to many individuals with ASD in forensic services (Murphy, 2010a). In their study, MacDonald et al. (2017) investigated the challenges and positive experiences of staff members working with sexual offenders who have a diagnosis of ASD. In order to do this, they utilised a semi-structured interview to investigate the challenges and benefits of working with this particular group. MacDonald et al. (2017) interviewed a total of eight participants who worked on the autism specialist ward at a forensic secure hospital in the UK. One of the key findings from the study was the number of challenges that the staff group face and the majority of the staff stated that they would benefit from in-depth training in ASD. The study indicated that further training, more support and "higher levels of staffing may be indicators of organisational intervention points" (p. 49). Additionally, staff members would benefit from training on the difficulties in successfully treating sex offenders who have ASD. Such training would help staff to manage their expectations in the level of impact and change that they can expect to see as a result of offence focused treatment (MacDonald et al., 2017).

Lastly, in the study by Esan et al. (2015) reported earlier in the section on prevalence, they investigated the characteristics of those with ASD treated within a 64-bed specialised forensic ID hospital in England compared to those without ASD. Of the 138 (cohort of patients treated over a six-year period), 42 (30 per cent) had an ASD. Compared to a group of patients without ASD, they found that in the ASD group, there were significantly lower rates of personality disorders and harmful use or dependence on drugs. However, in the ASD group, the rate of self-harm was significantly higher. Regarding length of stay and direction of care pathway, there were no significant differences between the two groups. The ASD group was found less likely to be subject to criminal sections or restriction orders compared to the group without ASD. Despite some of the differences found between the two groups, their treatment outcomes appear to be similar. Esan et al. (2015) argue that these findings indicate that "the diagnostic category of ASD alone may be inadequate in predicting the treatment outcome" (p. 193). Esan et al. (2015) argue that their findings indicate that there is a need to identify "distinct typologies" within patients with ASD.

\section{Discussion}

In total, 12 studies were included in this review. Only three studies looked at the prevalence of ASD in secure psychiatric hospitals (Scragg and Shah, 1994; Hare et al., 1999; Esan et al., 2015). All three studies indicated a prevalence of ASD within the secure forensic settings which was higher than that found in the general population. Only one study evaluated the clinical utility of the $A Q$ screening tool to assess self-reported autistic traits in secure psychiatric settings (Murphy, 2011). Only three studies explored any type of characteristics of patients with ASD detained in secure psychiatric hospitals (Murphy, 2003; Haw et al., 2013; Murphy, 2014). Interestingly, there was only one study identified which investigated the experiences or QoL of patients with an ASD detained in secure psychiatric care (Murphy, Chiu, Triantafyllopoulou, Barnoux, Blake, Cooke, Forrester-Jones, Gore and Beecham, 2017; Murphy, Gardner and Freeman, 2017; Murphy, Murphy, Mullens and Mullens, 2017). Only two studies were identified which investigated awareness, knowledge and/or views regarding patients with ASD held by staff working within secure psychiatric hospitals (Misra et al., 2013; Murphy and McMorrow, 2015). Only three studies were identified which investigated the effectiveness of interventions or treatment of patients with ASD in secure psychiatric hospitals (Murphy, 2010a; Esan et al., 2015; MacDonald et al., 2017). The study by Esan et al. (2015) was also included in the section on prevalence. 


\section{Screening for ASD: the clinical utility of the $A Q$ with forensic psychiatric patients}

The autism-spectrum quotient (AQ) (Woodbury-Smith et al., 2005) appears to be clinically useful in assessing the presence of ASD among patients admitted to HSPC. A recent study identified and described a number of screening tools for ASD that can support clinicians or researchers in trying to determine whether a more comprehensive ASD assessment is warranted (Sappok et al., 2015). Interestingly, only one study was identified in the present review which investigated the clinical utility of an ASD screening tool in forensic psychiatric patients with ASD (Murphy, 2011). In his paper, Murphy (2011) highlighted the urgent need for a forensic version of the AQ. Despite the clinical utility of the AQ in assessing the presence of ASD among patients admitted to high security psychiatric care, there are significant issues related with symptom validity (which are common to all self-report instruments). Importantly, the use of the AQ may be limited only to those individuals with sufficient literacy skills. There have been a number of studies which have found "extremely poor literacy skills" in prisoners for instance (e.g. Creese, 2016). Given the well-established high rate of patients and prisoners with poor literacy skills, Murphy (2011) recommends the need for an adapted version of the AQ which could be conducted using a semi-structured interview approach.

McCarthy et al. (2015) have also highlighted a number of studies which reported limitations on using the $\mathrm{AQ}$ as a diagnostic screen rather than as a tool to identify specific traits of autism (e.g. Hoekstra et al., 2008; Sizoo et al., 2009). Another important issue with the currently employed screening tools are their cultural sensitivity, particularly within a forensic setting such as a prison. In a study carried out by McCarthy et al. (2015), their findings indicated that prisoners from black or minority ethnicity backgrounds were at increased risk of their neurodevelopmental disorders and difficulties (NDD) symptoms going unrecognised by the current screening instruments. McCarthy et al. (2015) found that screening methods in their study identified "more white prisoners with NDD than was representative of the broader prison population, despite a lack of sampling or referral bias". This is consistent with the findings from other studies (e.g. Fazio et al., 2012).

\section{The need to adapt risk assessment tools for offenders with ASD}

Numerous clinicians and researchers have highlighted the urgent need for good practice guidelines in order to assess risk in individuals with a diagnosis of ASD (Murphy, 2013). Such an "ASD sensitive risk assessment guide" would comprise of both the factors which may increase the vulnerability of individuals with ASD to engage in offending behaviour (e.g. communication; cognitive and sensory impairments; social awareness, vulnerability, sensitivities, POs, unusual interests, anxiety provoking situations and obsessions or compulsions) and the factors that may be protective (e.g. an immediate environment which is well structured and unambiguous). (Murphy, 2010a; Gunasekaran, 2012). The majority of risk assessments explore a number of factors which are not relevant for offenders with ASD (e.g. presence of delusions, hallucinations, compliance with medication, use of illicit drugs and exacerbating psychotic symptoms) (Gunasekaran, 2012). In one of the papers identified in this review, Murphy (2010a) describes the case of $\mathrm{AB}$. This case draws attention to some important issues regarding risk management for individuals with ASD who are detained in HSPC. Numerous factors which are relevant for individuals with ASD who offend are not captured by conventional formal risk assessment guides such as The Historical Clinical Risk Management-20, Version 3 (HCR 20) (Douglas et al., 2013) (Webster, 1997). Similar to many individuals with ASD, for AB key risk factors for offending are associated with his communication, cognitive and sensory hypersensitivity impairments (Murphy, 2010a). Lastly, there is a need for more research to explore whether it is more appropriate to try and integrate ASD patients with other patients or whether a specialist ASD service within the hospital would be more useful (Murphy, 2010a).

\section{Length of acute care for patients with $A S D$}

The Autism Act (2009) introduced the adult autism strategy, which sets out how local services should be improved in order to address the needs of adults with ASD. In low and medium secure forensic settings, there are specialist services available to care for offenders with ASD. However, there is relatively little dedicated support in high secure settings (Misra et al., 2013). There are three 
high secure psychiatric hospitals in the UK. In secure care in the UK, individuals with ASD typically have longer durations of acute care (Hare et al., 1999; Haw et al., 2013; Bathgate, 2017). There have been a number of suggestions put forward to try and explain this. One suggestion that has been posited for this is the lack of specialist knowledge regarding their specific rehabilitation needs (Hare et al., 1999; Haw et al. , 2013). Another suggestion posited (Bathgate, 2017) is the lack of low secure services in the UK where the patient may progress through meeting rehabilitation goals. Regarding the overrepresentation of those with ASD in high secure forensic units (Scragg and Shah, 1994; Hare et al., 1999; Esan et al., 2015), the limited number of low-secure or community-based services may be one possible explanation for this (Bathgate, 2017).

\section{Limitations}

It is possible that the search terms utilised in the search for the present review did not capture all of the relevant research in the area of secure psychiatric hospitals and ASD. This was the justification for conducting the additional searches on "Google Scholar" using specific search criteria as outlined in the methods section in order to try and minimise this potential limitation as much as possible.

\section{Clinical implications}

Need for the development of an ASD screening tool which is not male-biased. Supporting the findings of Gillberg (1992), clinical impressions indicate that ASDs are exhibited in subtle ways in women. A meta-analysis found that compared to males with ASD, on average, females with ASD display less restricted, repetitive behaviours and interests (RRBI) (e.g. on the Autism Diagnostic Interview-Revised and/or the Autism Diagnostic Observation Schedule) (Van Wijngaarden-Cremers et al., 2014). Many females with ASD may go unidentified if RRBls continue to be regarded as key diagnostic criteria (Rynkiewicz et al., 2016). In order to address this issue, there is a need to collect a broad range of behaviours which go beyond those contained in the male-biased autism screening tools and diagnostic assessments currently used (Lai et al., 2015; Allely et al., 2018). The need for greater awareness and recognition of how autism symptomology can present in females with ASD and a tool to assist in the identification of possible ASD in females is clearly of great importance. Given the above, it would be important to carry out an empirical study of the women residents in the special hospitals. The majority of the samples in the studies identified in the present review included adult males.

Need for more staff training on ASD. A number of the studies identified in this review highlighted the need for more staff training on ASD (Misra et al., 2013; Murphy and McMorrow, 2015). Both these studies clearly highlight that in HSPC, despite some advancement with implementing the government's (Department of Health (DoH), 2010; see also: Walsh and Hall, 2012), there is a need for more awareness training in promoting staff confidence to work with this particular patient population (Misra et al., 2013; Murphy and McMorrow, 2015). The study by Misra et al. (2013) indicated that most staff were willing to train and work within a specialist ASD team.

\section{Future research directions}

Regarding therapy, Kelbrick and Radley (2013) have adopted cognitive analytic therapy as their main therapeutic approach in their unit because of its focus on reciprocal roles and relationships. They have found this therapy to have a positive impact on their patients anecdotally and highlight the need for research to empirically investigate psychotherapeutic approaches in adults with ASD. Additionally, more research is required looking at patients with ASD in secure forensic settings to determine which approaches and types of interventions are most effective in improving outcomes and the patient factors which are linked to good prognosis (Haw et al., 2013; Murphy, 2010a). A systematic review of the literature conducted by Melvin et al. (2017) revealed significant variability in the effectiveness of treatment programmes for offenders with ASDs and the impact of ASD symptoms on treatment outcomes. This review emphasised the need for more controlled research into these issues (Melvin et al. , 2017). Treatment outcomes would include: improvements in clinical symptoms and behaviour; QoL; patient experience of care (e.g. satisfaction); length of hospital stay; 
the use of "reactive" or "restrictive" interventions (for instance, the use of physical interventions and seclusion, pro re nata medication or a change in observation levels) and re-offending and risk (these are some of the treatment outcomes that have been used in a number of studies, e.g. Morrissey et al., 2017).

More research is also needed to examine both the individual and environmental factors which may increase the vulnerability in some individuals with ASD towards developing and acting on problematic POs. In the study by Murphy (2014), identified in the present review, it was found that, compared to those patients with ASD whose offending was linked to pursuing a PO, individuals with offending which was not linked to pursuing a PO appear to have more complex co-morbid psychiatric presentations (e.g. psychosis or a personality disorder). Further research is also needed to explore alcohol and illicit substances use in patients in secure psychiatric hospitals (Murphy, 2003).

Despite the growing body of research investigating the association between ASD and offending (e.g. Mawson et al., 1985; Baron-Cohen, 1988; Murrie et al., 2002; Schwartz-Watts, 2005; Woodbury-Smith et al., 2010; Radley and Shaherbano, 2011; Søndenaa et al., 2014), there is currently no tool to aid practitioners when assessing individuals with ASD who have offended. In their paper, Shine et al. (2016) outline the initial development of a framework which would aid clinicians in their case formulation for individuals with ASD who have been convicted. Information on the presence of ASD features from an individual's developmental history, index offence and offence paralleling behaviours would be obtained by the clinician in the proposed framework outlined in the paper. As a result, an informed assessment of the possible contribution of ASD to offending could be made (Shine et al., 2016).

\section{Conclusion}

There are a number of challenges to treatment in individuals with ASD due to the idiosyncratic and heterogeneous nature of the condition. Given the lack of a well-established evidence base, "individual case formulation informed by multidisciplinary assessments is essential to their rehabilitation" (Barkham et al., 2013, p. 14). As emphasised by Murphy (2010b), for patients with ASDs, forensic services struggle to manage and provide adequate placements. Staff awareness of ASD is crucial to the effective management of patients with ASD, and it has been strongly advocated that this training is mandatory (Murphy and McMorrow, 2015; Murphy, Murphy, Mullens, and Mullens, 2017). As highlighted by Murphy (2011), poor literacy skills are common in many prisoners and patients which necessitates the need to adapt the currently used $A Q$, perhaps enabling the tool to be delivered in a semi-structured interview. One common issue which arose during the use of the $A Q$ with the patients with ASD was the difficulty that many had in deciding on one answer. Moreover, some items in the AQ are difficult for many individuals to directly relate to (Murphy, 2011). There is also a growing concern over the clinical utility of the AQ and not just in forensic settings (e.g. Ashwood et al., 2016). This suggests the need for the development of an ASD screening tool for use in forensic settings and one for use in community settings.

\section{Reference}

Ali, A., Ghosh, S., Strydom, A. and Hassiotis, A. (2016), "Prisoners with intellectual disabilities and detention status: findings from a UK cross sectional study of prisons", Research in Developmental Disabilities, Vol. 53, pp. 189-97, available at: www.sciencedirect.com/science/article/pii/S0891422216300245

Allely, C. (2015), "Experiences of prison inmates with autism spectrum disorders and the knowledge and understanding of the spectrum amongst prison staff: a review", Journal of Intellectual Disabilities and Offending Behaviour, Vol. 6 No. 2, pp. 55-67.

Allely, C.S. and Creaby-Attwood, A. (2016), "Sexual offending and autism spectrum disorders", Journal of Intellectual Disabilities and Offending Behaviour, Vol. 7 No. 1, pp. 35-51.

Allely, C.S., Wood, T. and Gillberg, C. (2018), "The importance of identifying vulnerable females and males with autism in the prison environment".

American Psychiatric Association (2000), Diagnostic and Statistical Manual of Mental Disorders, 4th rev. ed., American Psychiatric Association, Washington, DC. 
American Psychiatric Association (2013), Diagnostic and Statistical Manual of Mental Disorders, 5th ed., American Psychiatric Association, Washington, DC.

Antshel, K.M., Zhang-James, Y., Wagner, K., Ledesma, A. and Faraone, S.V. (2016), "An update on the comorbidity of ASD and ADHD: a focus on clinical management", Expert Review of Neurotherapeutics, Vol. 16 No. 3, pp. 279-93.

Ashwood, K.L., Gillan, N., Horder, J., Hayward, H., Woodhouse, E., McEwen, F.S., Findon, J., Eklund, H., Spain, D., Wilson, C.E., Cadman, T., Young, S., Stoencheva, V., Murphy, C.M., Robertson, D., Charman, T., Bolton, P., Glaser, K., Asherson, P., Simonoff, E. and Murphy, D.G. (2016), "Predicting the diagnosis of autism in adults using the autism-spectrum quotient (AQ) questionnaire", Psychological Medicine, Vol. 46 No. 12, pp. 2595-604.

Attwood, T. (1998), Asperger's Syndrome, Jessica Kingsley Publishers, Philadelphia, PA.

Attwood, T. (2006), Autism, Access and Inclusion on the Front Line: Confessions of an Autism Anorak, Jessica Kingsley Publishers.

Autism Act (2009), "Printed in the UK by The Stationery Office Limited under the authority and superintendence of Carol Tullo", Controller of Her Majesty's Stationery Office and Queen's Printer of Acts of Parliament, available at: www.legislation.gov.uk/ukpga/2009/15/pdfs/ukpga_20090015_en.pdf (accessed 16 June 2017).

Baird, G., Charman, T., Baron-Cohen, S., Cox, A., Swettenham, J., Wheelwright, S. and Drew, A. (2000), "A screening instrument for autism at 18 months of age: a 6 year follow-up study", Journal of American Academy of Child and Adolescent Psychiatry, Vol. 39 No. 6, pp. 694-702.

Baird, G., Simonoff, E., Pickles, A., Chandler, S., Loucas, T., Meldrum, D. and Charman, T. (2006), "Prevalence of disorders of the autism spectrum in a population cohort of children in South Thames: the special needs and autism project (SNAP)", Lancet, Vol. 368 No. 9531, pp. 210-15.

Barkham, E., Gunasekaran, S. and Lovelock, C. (2013), "Medium secure care: forensic aspects of autism and Asperger's syndrome", Journal of Intellectual Disabilities and Offending Behaviour, Vol. 4 Nos 1/2, pp. 9-16.

Baron-Cohen, S., Wheelwright, S., Skinner, R., Martin, J. and Clubley, E. (2001), "The autism spectrum quotient $(A Q)$ : evidence from Asperger's syndrome/high functioning autism, males and females, scientists and mathematicians", Journal of Autism and Developmental Disorders, Vol. 31 No. 1, pp. 5-17.

Baron-Cohen, S. (1988), "An assessment of violence in a young man with Asperger's syndrome", Journal of Child Psychology and Psychiatry, Vol. 29 No. 3, pp. 351-60.

Bathgate, D. (2017), "ASD and offending: reflections of practice in from a New Zealand perspective", Journal of Intellectual Disabilities and Offending Behaviour, Vol. 8 No. 2, pp. 90-8.

Bertrand, J., Mars, A., Boyle, C., Bove, F., Yeargin-Allsopp, M. and Decoufle, P. (2001), "Prevalence of autism in a United States population: the Brick Township, New Jersey, investigation", Pediatrics, Vol. 108 No. 5, pp. 1155-61.

Boer, H., Alexander, R., Devapriam, J., Torales, J., Ng, R., Castaldelli-Maia, J. and Ventriglio, A. (2016), "Prisoner mental health care for people with intellectual disability", International Journal of Culture and Mental Health, Vol. 9 No. 4, pp. 442-6.

Bölte, S., Dziobek, I. and Poustka, F. (2009), "Brief report: the level and nature of autistic intelligence revisited", Journal of Autism and Developmental Disorders, Vol. 39 No. 4, pp. 678-82.

Bölte, S. and Poustka, F. (2002), "The relation between general cognitive level and adaptive behavior domains in individuals with autism with and without co-morbid mental retardation", Child Psychiatry and Human Development, Vol. 33 No. 2, pp. 165-72.

Bonora, E., Graziano, C., Minopoli, F., Bacchelli, E., Magini, P., Diquigiovanni, C., Lomartire, S., Bianco, F., Vargiolu, M., Parchi, P., Marasco, E., Mantovani, V., Rampoldi, L., Trudu, M., Parmeggiani, A., Battaglia, A., Mazzone, L., Tortora, G., Maestrini, E., Seri, M. and Romeo, G. (2014), "Maternally inherited genetic variants of CADPS2 are present in autism spectrum disorders and intellectual disability patients", EMBO Molecular Medicine, Vol. 6 No. 6, pp. 795-809.

Brugha, T.S., McManus, S., Bankart, J., Scott, F., Purdon, S., Smith, J., Bebbington, P., Jenkins, R. and Meltzer, H. (2011), "Epidemiology of autism spectrum disorders in adults in the community in England", Archives of General Psychiatry, Vol. 68 No. 5, pp. 459-65. 
Bruggink, A., Huisman, S., Vuijk, R., Kraaij, V. and Garnefski, N. (2016), "Cognitive emotion regulation, anxiety and depression in adults with autism spectrum disorder", Research in Autism Spectrum Disorders, Vol. 22, pp. 34-44, available at: www.sciencedirect.com/science/article/pii/S1750946715300027

Carlsson, L.H., Norrelgen, F., Kjellmer, L., Westerlund, J., Gillberg, C. and Fernell, E. (2013), "Coexisting disorders and problems in preschool children with autism spectrum disorders", Scientific World Journal, avaialable at: https://pdfs.semanticscholar.org/72c1/673bda0fOaceca8ceaccb51f24a9b0ab9b20.pdf

Centers for Disease Control and Prevention (2014), "Developmental Disabilities Monitoring Network Surveillance Year 2010 Principal Investigators, Prevalence of autism spectrum disorder among children aged 8 years - autism and developmental disabilities monitoring network, 11 sites, United States, 2010", Morbidity and Mortality Weekly Report. Surveillance Summaries, Vol. 63 No. 2, pp. 1-21.

Chakrabarti, S. and Fombonne, E. (2005), "Pervasive developmental disorders in preschool children: confirmation of high prevalence", American Journal of Psychiatry, Vol. 162 No. 6, pp. 1133-41.

Chaplin, E. and McCarthy, J. (2014), "Autism spectrum disorder and offending - a UK perspective", Autism Spectrum Quarterly, pp. 14-6, available at: www.forensicpsychology.org/HolmesASDArticle.pdf

Chaplin, E., McCarthy, J. and Underwood, L. (2013), "Autism spectrum conditions and offending: an introduction to the special edition", Journal of Intellectual Disabilities and Offending Behaviour, Vol. 4 Nos 1/2, pp. 5-8.

Charman, T., Pickles, A., Simonoff, E., Chandler, S., Loucas, T. and Baird, G. (2011), "IQ in children with autism spectrum disorders: data from the Special Needs and Autism Project (SNAP)", Psychological Medicine, Vol. 41 No. 3, pp. 619-27.

Chen, M.H., Wei, H.T., Chen, L.C., Su, T.P., Bai, Y.M., Hsu, J.W. and Chen, Y.S. (2015), "Autistic spectrum disorder, attention deficit hyperactivity disorder, and psychiatric comorbidities: a nationwide study", Research in Autism Spectrum Disorders, Vol. 10, pp. 1-6, available at: www.sciencedirect.com/science/ article/pii/S1750946714002554

Chiang, H.L. and Gau, S.S.F. (2016), "Comorbid psychiatric conditions as mediators to predict later social adjustment in youths with autism spectrum disorder", Journal of Child Psychology and Psychiatry, Vol. 57 No. 1, pp. 103-11.

Cooper, P. and Allely, C.S. (2017), "You can't judge a book by its cover: evolving professional responsibilities, liabilities and 'judgecraft' when a party has Asperger's syndrome”, Northern Ireland Legal Quarterly, Vol. 68 No. 1, pp. 35-58.

Cootes, J. (2016), "Breaching orders: apprehended violence orders a gateway to the criminal justice system for persons with intellectual disabilities", Journal of Intellectual Disability Research, Vol. 60 No. 7, p. 776, available at: https://insights.ovid.com/intellectual-disability-research/jidr/2016/07/000/breaching-ordersapprehended-violence-gateway/766/00002547

Creese, B. (2016), "An assessment of the English and maths skills levels of prisoners in England", London Review of Education, Vol. 14 No. 3, pp. 13-30.

De Bildt, A., Sytema, S., Kraijer, D. and Minderaa, R. (2004), "Prevalence of pervasive developmental disorders in children and adolescents with mental retardation", Journal of Child Psychology and Psychiatry, Vol. 46, pp. 275-86.

Department of Health (2010), “'Fulfilling and Rewarding Lives': the strategy for adults with autism in England”, HMSO, London.

Deth, R.C. (2012), "Genomics, intellectual disability, and autism", The New England Journal of Medicine, Vol. 366 No. 23, pp. 2231-2.

Douglas, K.S., Hart, S.D., Webster, C.D. and Belfrage, H. (2013), HCR-20V3: Assessing Risk of Violence - User Guide, Mental Health, Law, and Policy Institute, Simon Fraser University, Burnaby.

Eadens, D.M., Cranston-Gingras, A., Dupoux, E. and Eadens, D.W. (2016), "Police officer perspectives on intellectual disability", Policing: An International Journal of Police Strategies and Management, Vol. 39 No. 1, pp. 222-35.

Ehlers, S. and Gillberg, C. (1993), "The epidemiology of Asperger syndrome”, Journal of Child Psychology and Psychiatry, Vol. 34 No. 8, pp. 1327-50.

English, K. and Heil, P. (2005), "Prison rape: what we know today”, Corrections Compendium, Vol. 30 No. 5 , pp. 1-8. 
Esan, F., Chester, V., Gunaratna, I.J., Hoare, S. and Alexander, R.T. (2015), "The clinical, forensic and treatment outcome factors of patients with autism spectrum disorder treated in a forensic intellectual disability service", Journal of Applied Research in Intellectual Disabilities, Vol. 28 No. 3, pp. 193-200.

Fazio, R.L., Pietz, C.A. and Denney, R.L. (2012), "An estimate of the prevalence of autism spectrum disorders in an incarcerated population", Open Access Journal of Forensic Psychology, Vol. 4, pp. 69-80, available at: www.researchgate.net/profile/Rachel_Fazio/publication/261872792_An_estimate_of_the_prevalence_of_ autism-spectrum_disorders_in_an_incarcerated_population/links/0a85e535b311b9f416000000/Anestimate-of-the-prevalence-of-autism-spectrum-disorders-in-an-incarcerated-population.pdf

Fernell, E., Eriksson, M.A. and Gillberg, C. (2012), "Early diagnosis of autism and impact on prognosis: a narrative review", Clinical Epidemiology, Vol. 5, pp. 33-43, available at: www.ncbi.nlm.nih.gov/pmc/articles/ PMC3583438/

Fombonne, E. (2003), "Epidemiological surveys of autism and other pervasive developmental disorders: an update", Journal of Autism and Developmental Disorders, Vol. 33 No. 4, pp. 365-82.

Fombonne, E. (2009), "Epidemiology of pervasive developmental disorders", Pediatric Research, Vol. 65 No. 6, pp. 591-8.

Gaus, V. (2007), Cognitive Behaviour Therapy for Adult Asperger's Syndrome, The Guilford Press, New York, NY and London.

Ghaziuddin, M., Ghaziuddin, N. and Greden, J. (2002), "Depression in persons with autism: implications for research and clinical care", Journal of Autism and Developmental Disorders, Vol. 32 No. 4, pp. 299-306.

Gillberg, C. (1992), "The Emmanuel Miller Memorial Lecture 1991: autism and autistic-like conditions: subclasses among disorders of empathy", Journal of Child Psychology and Psychiatry, Vol. 33 No. 5, pp. 813-42.

Gillberg, C., Steffenburg, S. and Schaumann, H. (1991), "Is autism more common now than ten years ago?", The British Journal of Psychiatry, Vol. 158 No. 3, pp. 403-09.

Gillberg, C. and Gillberg, C. (1989), "Asperger's syndrome-some epidemiological considerations: a research note", Journal of Child Psychology and Psychiatry, Vol. 30 No. 4, pp. 631-8.

Glaser, W. and Deane, K. (1999), "Normalisation in an abnormal world: a study of prisoners with an intellectual disability", International Journal of Offender Therapy and Comparative Criminology, Vol. 43 No. 3 , pp. 338-56.

Gordon, R. (2002), "Asperger syndrome: one prisoner's experience”, Prison Service Journal, pp. 2-4.

Gunasekaran, S. (2012), "Assessment and management of risk in autism”, Advances in Mental Health and Intellectual Disabilities, Vol. 6 No. 6, pp. 314-20.

Hammond, R.K. and Hoffman, J.M. (2014), "Adolescents with high-functioning autism: an investigation of comorbid anxiety and depression", Journal of Mental Health Research in Intellectual Disabilities, Vol. 7 No. 3, pp. 246-63.

Hare, D.J. and Paine, C. (1997), "Developing cognitive behavioural treatments for people with Asperger's syndrome", Clinical Psychology Forum, pp. 5-8.

Hare, D.J., Gould, J., Mills, R. and Wing, L. (1999), "A preliminary study of individuals with autistic spectrum disorders in three special hospitals in England", National Autistic Society, available at: www.aspiresrelationships.com/3hospitals.pdf (accessed 29 May 2017).

Haskins, B.G. and Silva, J.A. (2006), "Asperger's disorder and criminal behavior: forensic-psychiatric considerations asperger's disorder and criminal behavior: forensic-psychiatric considerations", Journal of American Academy of Psychiatry Law, Vol. 34 No. 3, pp. 374-84.

Haw, C., Radley, J. and Cooke, L. (2013), "Characteristics of male autistic spectrum patients in low security: are they different from non-autistic low secure patients?", Journal of Intellectual Disabilities and Offending Behaviour, Vol. 4 Nos 1/2, pp. 24-32.

Hoekstra, R.A., Bartels, M., Cath, D.C. and Boomsma, D.I. (2008), "Factor structure, reliability and criterion validity of the autism-spectrum quotient (AQ): a study in Dutch population and patient groups", Journal of Autism and Developmental Disorders, Vol. 38 No. 8, pp. 1555-66.

Jordan, R. (1999), "Evaluating practice: problems and possibilities”, Autism, Vol. 3 No. 4, pp. 411-34. 
Keen, D. and Ward, S. (2004), "Autistic spectrum disorder: a child population profile", Autism, Vol. 8 No. 1, pp. 39-48.

Kelbrick, M. and Radley, J. (2013), "Forensic rehabilitation in Asperger syndrome: a case report”, Journal of Intellectual Disabilities and Offending Behaviour, Vol. 4 Nos 1/2, pp. 60-4.

King, C. and Murphy, G.H. (2014), "A systematic review of people with autism spectrum disorder and the criminal justice system", Journal of Autism and Developmental Disorders, Vol. 44 No. 11, pp. 2717-33.

La Malfa, G., Lassi, S., Bertelli, M., Salvini, R. and Placidi, G.F. (2004), "Autism and intellectual disability: a study of prevalence on a sample of the Italian population", Journal of Intellectual Disability Research, Vol. 48 No. 3, pp. 262-7.

Lai, M.C., Lombardo, M.V., Auyeung, B., Chakrabarti, B. and Baron-Cohen, S. (2015), "Sex/gender differences and autism: setting the scene for future research", Journal of the American Academy of Child and Adolescent Psychiatry, Vol. 54 No. 1, pp. 11-24.

Lai, M.C., Baron-Cohen, S. and Buxbaum, J.D. (2015), "Understanding autism in the light of sex/gender", Molecular Autism, Vol. 6, pp. 24-8.

Ledingham, R. and Mills, R. (2015), "A preliminary study of autism and cybercrime in the context of international law enforcement”, Advances in Autism, Vol. 1 No. 1, pp. 2-11.

Lewis, A., Pritchett, R., Hughes, C. and Turner, K. (2015), "Development and implementation of autism standards for prisons", Journal of Intellectual Disabilities and Offending Behaviour, Vol. 6 No. 2, pp. 68-80.

Liberati, A., Altman, D.G., Tetzlaff, J., Mulrow, C., Gøtzsche, P.C., loannidis, J.P., Clarke, M., Devereaux, P.J., Kleijnen, J. and Moher, D. (2009), "The PRISMA statement for reporting systematic reviews and metaanalyses of studies that evaluate health care interventions: explanation and elaboration", Annals of Internal Medicine, Vol. 151 No. 4, pp. W65-94.

Lyall, K., Croen, L., Daniels, J., Fallin, M.D., Ladd-Acosta, C., Lee, B.K., Park, B.Y., Snyder, N.W., Schendel, D., Volk, H., Windham, G.C. and Newschaffer, C. (2017), "The changing epidemiology of autism spectrum disorders”, Annual Review of Public Health, Vol. 38, pp. 81-102.

Love, C. and Morrison, E. (2002), Forensic Psychiatric Nursing Struggling to Happen, Failing to Thrive, Forensic Nurse.

McAdam, P. (2009), "Knowledge and understanding of the autism spectrum amongst prison staff", Good Autism Practice (GAP), Vol. 10 No. 1, pp. 19-25.

McCarthy, J., Chaplin, E., Underwood, L., Forrester, A., Hayward, H., Sabet, J., Young, S., Asherson, P., Mills, R. and Murphy, D. (2015), "Screening and diagnostic assessment of neurodevelopmental disorders in a male prison", Journal of Intellectual Disabilities and Offending Behaviour, Vol. 6 No. 2, pp. 102-11.

McPartland, J.C., Reichow, B. and Volkmar, F.R. (2012), "Sensitivity and specificity of proposed DSM-V diagnostic criteria for autism spectrum disorder", Journal of the American Academy of Child and Adolescent Psychiatry, Vol. 51 No. 4, pp. 368-83.

MacDonald, S., Clarbour, J., Whitton, C. and Rayner, K. (2017), "The challenges of working with sexual offenders who have autism in secure services", Journal of Intellectual Disabilities and Offending Behaviour, Vol. 8 No. 1, pp. 41-54, available at: www.emeraldinsight.com/doi/abs/10.1108/JIDOB-10-2016-0020

Magnússon, P. and Saemundsen, E. (2001), "Prevalence of autism in Iceland", Journal of Autism and Developmental Disorders, Vol. 31 No. 2, pp. 153-63.

Martin, T. (2001), "Something special: forensic psychiatric nursing", Journal of Psychiatric and Mental Health Nursing, Vol. 8 No. 1, pp. 25-32.

Matson, J.L. and Shoemaker, M. (2009), "Intellectual disability and its relationship to autism spectrum disorders", Research in Developmental Disabilities, Vol. 30 No. 6, pp. 1107-14.

Matson, J.L. and Williams, L.W. (2014), "Depression and mood disorders among persons with autism spectrum disorders", Research in Developmental Disabilities, Vol. 35 No. 9, pp. 2003-07.

Mawson, D.C., Grounds, A. and Tantam, D. (1985), "Violence and Asperger's syndrome: a case study", The British Journal of Psychiatry, Vol. 147, pp. 566-9, available at: www.ncbi.nlm.nih.gov/pubmed/4075056

Melvin, C.L., Langdon, P.E. and Murphy, G.H. (2017), "Treatment effectiveness for offenders with autism spectrum conditions: a systematic review”, Psychology, Crime and Law, Vol. 23 No. 8, pp. 748-76. 
Mefford, H.C., Batshaw, M.L. and Hoffman, E.P. (2012), "Genomics, intellectual disability, and autism", New England Journal of Medicine, Vol. 366 No. 8, pp. 733-43.

Miller, J.S., Bilder, D., Farley, M., Coon, H., Pinborough-Zimmerman, J., Jenson, W. et al. (2012), "Autism spectrum disorder reclassified: a second look at the 1980s Utah/UCLA autism epidemiologic study", Journal of Autism and Developmental Disorders, Vol. 43, pp. 200-10.

Ministry of Justice (2015), "Prison population figures, population bulletin: weekly 7 August 2015", available at: www.gov.uk/government/statistics/prison-population-figures-2015 (accessed 5 December 2017).

Misra, P., Patel, M.K. and Edwards, J.E. (2013), "1834-The need for specialist service for offenders with autistic spectrum disorder within high secure psychiatric care", European Psychiatry, Vol. 28 No. S1, p. 1, available at: www.sciencedirect.com/science/article/pii/S0924933813767981

Moher, D., Liberati, A., Tetzlaff, J. and Altman, D.G. (2009), "Preferred reporting items for systematic reviews and meta-analyses: the PRISMA statement", Annals of Internal Medicine, Vol. 151 No. 4, pp. 264-9.

Morrissey, C., Langdon, P.E., Geach, N., Chester, V., Ferriter, M., Lindsay, W.R., McCarthy, J., Devapriam, J., Walker, D.M., Duggan, C. and Alexander, R. (2017), "A systematic review and synthesis of outcome domains for use within forensic services for people with intellectual disabilities", British Journal of Psychiatry Open, Vol. 3 No. 1, pp. 41-56.

Moss, P., Howlin, P., Savage, S., Bolton, P. and Rutter, M. (2015), "Self and informant reports of mental health difficulties among adults with autism findings from a long-term follow-up study", Autism, Vol. 19 No. 7, pp. 832-41.

Murphy, G.H., Gardner, J. and Freeman, M.J. (2017), "Screening prisoners for intellectual disabilities in three English prisons", Journal of Applied Research in Intellectual Disabilities, Vol. 30 No. 1, pp. 198-204.

Murphy, G.H., Chiu, P., Triantafyllopoulou, P., Barnoux, M., Blake, E., Cooke, J., Forrester-Jones, R.V.E., Gore, N.J. and Beecham, J.K. (2017), "Offenders with intellectual disabilities in prison: what happens when they leave?", Journal of Intellectual Disability Research, Vol. 61 No. 10, pp. 957-68.

Murphy, D., Murphy, D., Mullens, H. and Mullens, H. (2017), "Examining the experiences and quality of life of patients with an autism spectrum disorder detained in high secure psychiatric care", Advances in Autism, Vol. 3 No. 1, pp. 3-14.

Murphy, D. and McMorrow, K. (2015), "View of autism spectrum conditions held by staff working within a high secure psychiatric hospital”, Journal of Forensic Practice, Vol. 17 No. 3, pp. 231-40.

Murphy, D. (2003), "Admission and cognitive details of male patients diagnosed with Asperger's syndrome detained in a special hospital: comparison with a schizophrenia and personality disorder sample", The Journal of Forensic Psychiatry, Vol. 14 No. 3, pp. 506-24.

Murphy, D. (2010a), "Extreme violence in a man with an autistic spectrum disorder: assessment and treatment within high-security psychiatric care", The Journal of Forensic Psychiatry and Psychology, Vol. 21 No. 3, pp. 462-77.

Murphy, D. (2010b), "Understanding offenders with autism-spectrum disorders: what can forensic services do?", Advances in Psychiatric Treatment, Vol. 16 No. 1, pp. 44-6.

Murphy, D. (2011), "Autism spectrum quotient (AQ) profiles among male patients within high security psychiatric care: comparison with personality and cognitive functioning", Journal of Forensic Psychiatry and Psychology, Vol. 22 No. 4, pp. 518-34.

Murphy, D. (2013), "Risk assessment of offenders with an autism spectrum disorder", Journal of Intellectual Disabilities and Offending Behaviour, Vol. 4 Nos 1/2, pp. 33-41.

Murphy, D. (2014), "Self-reported anger among individuals with an autism spectrum disorder detained in high security psychiatric care: do preoccupations have an influence?", The Journal of Forensic Psychiatry and Psychology, Vol. 25 No. 1, pp. 100-12.

Murphy, D. (2017), "Sense and sensibility: forensic issues with autism spectrum disorders", in Barahona Corrêa, B. and van der Gaag, R.J. (Eds), Autism Spectrum Disorders in Adults, Springer International Publishing, pp. 247-66, available at: www.springer.com/gb/book/9783319427119?wtmc=ThirdParty.SpringerLink.3. EPR653.About_eBook

Murrie, D.C., Warren, J.I., Kristiansson, M. and Dietz, P.E. (2002), "Asperger's syndrome in forensic settings", International Journal of Forensic Mental Health, Vol. 1 No. 1, pp. 59-70. 
Myers, F. (2004), On the Borderline? People with Learning Disabilities and/or Autistic Spectrum Disorders in Secure, Forensic and Other Specialist Settings, The Stationery Office, Edinburgh.

Newman, C., Cashin, A. and Waters, C. (2015), "A hermeneutic phenomenological examination of the lived experience of incarceration for those with autism", Issues in Mental Health Nursing, Vol. 36 No. 8 , pp. 632-40.

Newschaffer, C.J., Croen, L.A., Daniels, J., Giarelli, E., Grether, J.K., Levy, S.E., Mandell, D.S., Miller, L.A., Pinto-Martin, J., Reaven, J., Reynolds, A.M., Rice, C.E., Schendel, D. and Windham, G.C. (2007), "The epidemiology of autism spectrum disorders", Annual Review of Public Health, Vol. 28, pp. 235-58, available at: http://europepmc.org/abstract/med/17367287

Nicholl, J., Waters, W., Mulley, J.C., Suwalski, S., Brown, S., Hull, Y. and Mcgregor, L. (2014), "Cognitive deficit and autism spectrum disorders: prospective diagnosis by array CGH", Pathology - Journal of the RCPA, Vol. 46 No. 1, pp. 41-5.

Oliver, J., Huxley, P., Bridges, K. and Mohammed, H. (1996), Quality of Life and Mental Health Services, Routledge, London.

Oliveira, G., Ataíde, A., Marques, C., Miguel, T.S., Coutinho, A.M., Mota-Vieira, L., Gonçalves, E., Lopes, N.M., Rodrigues, V., Carmona da Mota, H. and Vicente, A.M. (2007), "Epidemiology of autism spectrum disorder in Portugal: prevalence, clinical characterization, and medical conditions", Developmental Medicine and Child Neurology, Vol. 49 No. 10, pp. 726-33.

Postorino, V., Fatta, L.M., Sanges, V., Giovagnoli, G., De Peppo, L., Vicari, S. and Mazzone, L. (2016), "Intellectual disability in autism spectrum disorder: investigation of prevalence in an Italian sample of children and adolescents", Research in Developmental Disabilities, Vol. 48, pp. 193-201, available at: www.ncbi.nlm. nih.gov/pubmed/26619372

Radley, J. and Shaherbano, Z. (2011), "Asperger syndrome and arson: a case study", Advances in Mental Health and Intellectual Disabilities, Vol. 5 No. 6, pp. 32-6.

Ritvo, E.R. (2012), "Postponing the proposed changes in DSM 5 for autistic spectrum disorder until new scientific evidence adequately supports them", Journal of Autism and Developmental Disorders, Vol. 42 No. 9, pp. 2021-2.

Robertson, C.E. and McGillivray, J.A. (2015), "Autism behind bars: a review of the research literature and discussion of key issues", The Journal of Forensic Psychiatry and Psychology, Vol. 26 No. 6, pp. 719-36.

Robinson, L., Spencer, M.D., Thomson, L.D., Stanfield, A.C., Owens, D.G., Hall, J. and Johnstone, E.C. (2012), "Evaluation of a screening instrument for autism spectrum disorders in prisoners", PLoS One, Vol. 7 No. 5, p. e36078.

Rynkiewicz, A., Schuller, B., Marchi, E., Piana, S., Camurri, A., Lassalle, A. and Baron-Cohen, S. (2016), "An investigation of the 'female camouflage effect' in autism using a computerized ADOS-2 and a test of sex/ gender differences", Molecular Autism, Vol. 7, p. 10, available at: www.researchgate.net/profile/Agnieszka_ Rynkiewicz2/publication/291343037_An_investigation_of_the_'female_camouflage_effect'_in_autism_ using_a_computerized_ADOS-2_and_a_test_of_sexgender_difference/links/56a0e88408ae21a5642 d5ae9/An-investigation-of-the-female-camouflage-effect-in-autism-using-a-computerized-ADOS-2-and-atest-of-sex-gender-difference.pdf

Sabet, J., Underwood, L., Chaplin, E., Hayward, H. and McCarthy, J. (2015), "Autism spectrum disorder, attention-deficit hyperactivity disorder and offending", Advances in Autism, Vol. 1 No. 2, pp. 98-107.

Sappok, T., Heinrich, M. and Underwood, L. (2015), "Screening tools for autism spectrum disorders", Advances in Autism, Vol. 1 No. 1, pp. 12-29.

Schwartz-Watts, D.M. (2005), "Asperger's disorder and murder", Journal of the American Academy of Psychiatry and the Law, Vol. 33 No. 3, p. 390.

Scragg, P. and Shah, A. (1994), "Prevalence of Asperger's syndrome in a secure hospital", The British Journal of Psychiatry, Vol. 165 No. 5, pp. 679-82.

Shine, J., Shine, J., Cooper-Evans, S. and Cooper-Evans, S. (2016), "Developing an autism specific framework for forensic case formulation", Journal of Intellectual Disabilities and Offending Behaviour, Vol. 7 No. 3, pp. 127-39.

Shively, R. (2004), "Treating offenders with mental retardation and developmental disabilities", Corrections Today, Vol. 66, pp. 84-7. 
Simonoff, E. (2012), "Autism spectrum disorder: prevalence and cause may be bound together", British Journal of Psychiatry, Vol. 201, pp. 88-9, available at: www.ncbi.nlm.nih.gov/pubmed/22859574

Sizoo, B.B., van den Brink, W., Gorissen-van Eenige, M., Koeter, M.W., van Wijngaarden-Cremers, P.J. and van der Gaag, R.J. (2009), "Using the autism-spectrum quotient to discriminate autism spectrum disorder from ADHD in adult patients with and without comorbid substance use disorder", Journal of Autism and Developmental Disorders, Vol. 39 No. 9, pp. 1291-7.

Søndenaa, E., Helverschou, S.B., Steindal, K., Rasmussen, K., Nilson, B. and Nøttestad, J.A. (2014), "Violence and sexual offending behavior in people with autism spectrum disorder who have undergone a psychiatric forensic examination", Psychological Reports, Vol. 115 No. 1, pp. 32-43.

Spielberger, C. (1999), The State Trait Anger Expression Inventory, Vol. 2, Psychological Assessment Resource, Odessa, FL.

Srivastava, A.K. and Schwartz, C.E. (2014), "Intellectual disability and autism spectrum disorders: causal genes and molecular mechanisms", Neuroscience \& Biobehavioral Reviews, Vol. 46, Part 2, pp. 161-74.

Taylor, M.J., Charman, T. and Ronald, A. (2015), "Where are the strongest associations between autistic traits and traits of ADHD? Evidence from a community-based twin study", European Child and Adolescent Psychiatry, Vol. 24 No. 9, pp. 1129-38.

Taylor, P.J., Leese, M., Williams, D., Butwell, M., Daly, R. and Larkin, E. (1998), "Mental disorder and violence: a special (high security) hospital survey”, British Journal of Psychiatry, Vol. 172 No. 3, pp. 218-26.

The National Autistic Society (2005), Autism: A Guide for Criminal Justice Professional, The National Autistic Society, London.

Tonnsen, B.L., Boan, A.D., Bradley, C.C., Charles, J., Cohen, A. and Carpenter, L.A. (2016), "Prevalence of autism spectrum disorders among children with intellectual disability", American Journal on Intellectual and Developmental Disabilities, Vol. 121 No. 6, pp. 487-500.

Underwood, L., McCarthy, J., Chaplin, E., Forrester, A., Mills, R. and Murphy, D. (2016), "Autism spectrum disorder traits among prisoners", Advances in Autism, Vol. 2 No. 3, pp. 106-17.

Underwood, L., Forrester, A., Chaplin, E. and McCarthy, J. (2013), "Prisoners with neurodevelopmental disorders", Journal of Intellectual Disabilities and Offending Behaviour, Vol. 4 Nos 1/2, pp. 17-23.

Van Wijngaarden-Cremers, P.J., van Eeten, E., Groen, W.B., Van Deurzen, P.A., Oosterling, I.J. and Van der Gaag, R.J. (2014), "Gender and age differences in the core triad of impairments in autism spectrum disorders: a systematic review and meta-analysis", Journal of Autism and Developmental Disorders, Vol. 44 No. 3, pp. 627-35.

Walsh, N. and Hall, I. (2012), "The autism strategy: implications for people with autism and for service development", Advances in Mental Health and Intellectual Disabilities, Vol. 6 No. 3, pp. 113-20.

Waterhouse, L. (2013), Rethinking Autism: Variation and Complexity, Academic Press, London.

Webster, C. (1997), The HCR 20 Assessing Risk for Violence, version two, Mental Health, Law and Policy Institute, Simon Fraser University, Forensic Psychiatric Services Commission of British Columbia, available at: www.citeulike.org/group/15748/article/9908347

Wechsler, D. (1997), Wechsler Adult Intelligence Scale WAIS III), 3rd ed., The Psychological Corporation, San Antonio, TX.

Wilkins, J. and Matson, J.L. (2009), "A comparison of social skills profiles in intellectually disabled adults with and without ASD”, Behavior Modification, Vol. 33 No. 2, pp. 143-55.

Wing, L., Gould, J. and Gillberg, C. (2011), "Autism spectrum disorders in the DSM-V: better or worse than the DSM-IV?", Research in Developmental Disabilities, Vol. 32 No. 2, pp. 768-73.

Wing, L. (1996), The Autistic Spectrum: A Guide for Parents and Professionals, Constable, London.

Wing, L. (1991), "The relationship between Asperger's syndrome and Kanner's autism”, in Frith, U. (Ed.), Autism and Asperger Syndrome, Cambridge University Press, Cambridge, pp. 93-121.

Woodbury-Smith, M., Clare, I., Holland, A.J., Watson, P.C., Bambrick, M., Kearns, A. and Staufenberg, E. (2010), "Circumscribed interests and 'offenders' with autism spectrum disorders: a case-control study", The Journal of Forensic Psychiatry and Psychology, Vol. 21 No. 3, pp. 366-77.

Woodbury-Smith, M.R., Robinson, J., Wheelwright, S. and Baron-Cohen, S. (2005), "Screening adults for Asperger syndrome using the AQ: a preliminary study of its diagnostic validity in clinical practice", Journal of Autism and Developmental Disorders, Vol. 35 No. 3, pp. 331-5. 


\section{Further reading}

Alexander, R.T., Crouch, K., Halstead, S. and Piachaud, J. (2006), "Long-term outcome from a medium secure service for people with intellectual disability", Journal of Intellectual Disability Research, Vol. 50 No. 4, pp. 305-15.

Alexander, R.T., Green, F.N., O’Mahony, B., Gunaratna, I.J., Gangadharan, S.K. and Hoare, S. (2010), "Personality disorders in offenders with intellectual disability: a comparison of clinical, forensic and outcome variables and implications for service provision", Journal of Intellectual Disability Research, Vol. 54 No. 7, pp. 650-8.

Alexander, R.T., Hiremath, A., Chester, V., Green, F.N., Gunaratna, I.J. and Hoare, S. (2011), "Evaluation of treatment outcomes from a medium secure unit for people with intellectual disability", Advances in Mental Health and Intellectual Disabilities, Vol. 5 No. 1, pp. 22-32.

Baron-Cohen, S., Wheelwright, S., Hill, J., Raste, Y. and Plumb, I. (2001), 'The 'Reading the Mind in the Eyes' test revised version: a study with normal adults and adults with Asperger's syndrome or high functioning autism", Journal of Child Psychology and Psychiatry, Vol. 42 No. 2, pp. 241-51.

Centre for Mental Health (2011), Pathways to Unlocking Secure Mental Health Care, Centre for Mental Health, London.

Dobbinson, S.J. and Dobbinson, S.J. (2016), "Systemizing and empathy in forensic ASD talk", Advances in Autism, Vol. 2 No. 4, pp. 179-90.

Hare, R.D. (1986), "Twenty years of experience with the Cleckley psychopath”, in Reid, W.H., Dorr, D., Walker, J.I. and Bonner, J.W. (Eds), Unmasking the Psychopath: Antisocial Personality and Related Syndromes, W.W. Norton, New York, NY, pp. 3-27.

Hare, R.D. (1980), "A research scale for the assessment of psychopathy in criminal populations", Personality and Individual Differences, Vol. 1 No. 2, pp. 111-9.

Millon, T. (1997), Millon Clinical Multiaxial Inventory-III (MCMI-III) Manual, 2nd ed., National Computer Systems, Minneapolis, MN.

Wing, L. (1997), "Asperger's syndrome: management requires diagnosis (editorial)", Journal of Forensic Psychiatry, Vol. 8 No. 2, pp. 253-7.

Wing, L. (1981), "Asperger's syndrome: a clinical account”, Psychological Medicine, Vol. 11 No. 1, pp. 115-29.

Wolff, S. (1995), Loners: The Life Paths of Unusual Children, Routledge, London.

\section{About the author}

Dr Clare S. Allely is a Reader in Forensic Psychology at the University of Salford, UK, and is an affiliate member of the Gillberg Neuropsychiatry Centre at Gothenburg University, Sweden. Clare is also an Honorary Research Fellow in the College of Medical, Veterinary and Life Sciences affiliated to the Institute of Health and Wellbeing at the University of Glasgow. She holds a PhD Degree in Psychology from the University of Manchester and has previously graduated with an MA (hons.) in Psychology from the University of Glasgow, an MRes Degree in Psychological Research Methods from the University of Strathclyde, and an MSc Degree in Forensic Psychology from Glasgow Caledonian University. Clare S. Allely can be contacted at: c.s.allely@salford.ac.uk

For instructions on how to order reprints of this article, please visit our website:

www.emeraldgrouppublishing.com/licensing/reprints.htm

Or contact us for further details: permissions@emeraldinsight.com 